\title{
Investigation of an Evaporative Cooler for Buildings in Hot and Dry Climates
}

\author{
R. Boukhanouf, H. G. Ibrahim, A. Alharbi, and M. Kanzari
}

\begin{abstract}
The paper presents a computer model and experimental results of a sub-wet bulb temperature evaporative cooling system for space cooling in buildings in hot and dry climates. The cooler uses porous ceramic materials as the wet media for water evaporation. Under selected test conditions of airflow dry bulb temperature of up to $45^{\circ} \mathrm{C}$ and relative humidity of up to $50 \%$, it was found that the supply air could be cooled to below the wet bulb temperature with a maximum cooling capacity of $280 \mathrm{~W} / \mathrm{m}^{2}$ of the wet ceramic surface area. It was also shown that the overall wet bulb effectiveness is greater than unity. This performance would make the system a potential alternative to conventional mechanical air conditioning systems in hot and dry regions.
\end{abstract}

Index Terms-Buildings air conditioning, evaporative cooling, heat and mass transfer, porous ceramics.

\section{INTRODUCTION}

Energy consumption in buildings stands at between $30-40 \%$ of the total primary energy use globally [1]. A major part of this is used to provide comfortable indoor climatic conditions for occupants. For example, in regions with hot climates energy for space cooling accounts for over $60 \%$ of the total energy used in buildings [1]. The growth in air conditioning systems in the world is mainly driven by an increase in living standards, affordability, population increase and cheap electrical energy in some regions such the Middle East. This has led many countries to build new power generation plants and extend grid infrastructure to meet peak electricity loads, which in turn impacts negatively on the environment through increased greenhouse gas emissions.

Current air conditioning market is dominated by mechanical vapour compression systems, which are energy intensive systems and suffer from low thermal performance in hot climate conditions. Hence, there is a renewed interest in the use of evaporative cooling for thermal comfort in buildings. The earliest use of evaporative cooling was by ancient Egypt and the Roman Empire using for example wet mats (cooling pads) over doors and windows to cool the indoor air when wind blew through the mats [2]. Evaporative cooling is widely found in Middle East and Persian

Manuscript received June 11, 2013; revised July 16, 2013. This publication was made possible by NPRP grant No. 4-407-2-153 from the Qatar National Research Fund (a member of Qatar Foundation). The statements made herein are solely the responsibility of the authors.

R. Boukhanouf and A. Alharbi are with The University of Nottingham, Department of Architecture and Built Environment, Nottingham, NG7 2RD, UK (e-mail: rabah.boukhanouf@nottingham.ac.uk, laxaa17@nottingham.ac.uk ).

H. G. Ibrahim and M. Kenzari are with Qatar University, Department of Architecture and Urban Planning, Doha, Qatar (e-mail: hatem_ibrahim@qu.edu.qa, meryem_kanzari@qu.edu.qa) architecture often integrated into the windcatchers. Evaporative cooling is a low carbon and economically feasible method for cooling buildings in hot and dry climates.

\section{EVAPorative CoOling TechnOlogy}

Evaporative cooling technologies could be classified into direct and indirect system.

\section{A. Direct Evaporative Cooling Systems}

Direct evaporative cooling is the process of evaporating liquid water to the surrounding air and causing its temperature to decease. A typical direct evaporative cooler, as shown in Fig. 1, uses a fan to draw in outside air through a pad wetting media and circulates the cool air through the building.

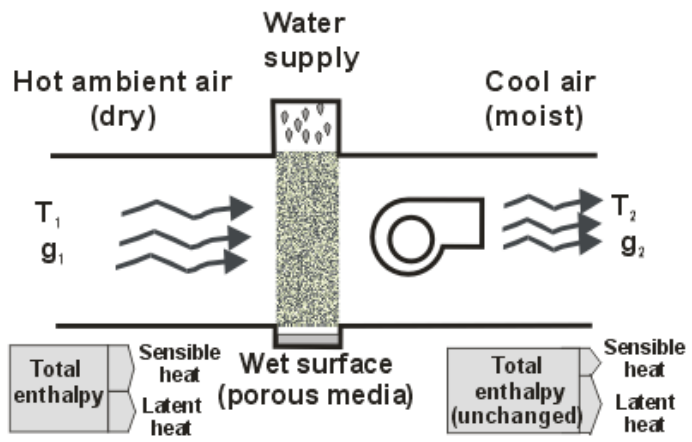

Fig. 1. Schematic of a direct evaporative cooling system

The energy required for evaporation of water is provided by the air, though at the expense of increasing its moisture content and decreasing its temperature. Since the process is adiabatic, the sensible heat loss by the air is balanced out by latent heat gain, which appears as moisture content increase. The heat and mass transfer between the warm dry air and water can be expressed as follows [3].

$$
\left(\dot{m}_{a} h_{1}+\dot{m}_{v 1} h_{v 1}\right)-\dot{m}_{w v} h_{f g}=\left(\dot{m}_{a} h_{2}+\dot{m}_{v 2} h_{v 2}\right)
$$

where $m_{a}, \mathrm{~h}_{1}$ and $\mathrm{h}_{2}$ are air mass flow rate, inlet and outlet enthalpy respectively. $m_{v 1}, h_{v 1}, m_{v 2}$ and $h_{v 2}$ are the water vapour inlet mass flow rate, enthalpy, outlet mass flow rate and enthalpy respectively. $m_{w v}$ and $h_{f g}$ are the water evaporation rate and latent heat of evaporation respectively. The amount of water required can be computed as:

$$
\dot{m}_{w v}=\dot{m}_{d a}\left(g_{2}-g_{1}\right)
$$

where $m_{d a}$ is dry air mass flow rate, $g_{1}$ and $g_{2}$ are the inlet and outlet air moisture content respectively.

The effectiveness of direct evaporative coolers is primarily influenced by the air wet bulb temperature and in a 
well-designed system the air could be cooled to within 2 to $3^{\circ} \mathrm{C}$ of the wet bulb temperature which presents a severe thermodynamic limitation.

\section{B. Indirect Evaporative Cooling and Sub Wet Bulb Temperature}

This has led several researchers to develop and modify the thermal process of direct evaporative cooling system to achieving sub-wet bulb temperature, referred to as Dew point or Sub-wet bulb temperature evaporative cooling. In this coolers arrangement, the air streams are separated into dry channel for supply air and wet channel for rejecting spent working air. The supply air in the dry channel is cooled indirectly by transferring its heat to the working air in the wet channel through a thin non-permeable channel wall. To achieve sub-wet bulb temperature, part of the cool air in the dry channel is diverted to accomplish the evaporation process in the wet channel, as shown in Fig. 2.

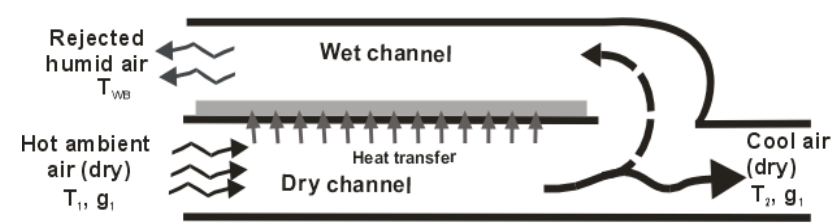

Fig. 2. A simple schematic of a sub wet bulb temperature indirect evaporative cooler.

The advantage of this arrangement is that the moisture content of the cooled air remains unchanged. Hsu et al. [4] carried out a theoretical and experimental study on two configurations of closed-loop wet surface heat exchangers to achieve sub-wet bulb temperature cooling through counter flow and cross flow air stream arrangements. Boxem et al. [5] presented a model for a compact counter flow Indirect Evaporative Cooler with finned exchanger. The performance of a $400 \mathrm{~m}^{3} / \mathrm{h}$ air flow rate cooler was analysed and showed that for inlet air temperatures higher than $24^{\circ} \mathrm{C}$ the model results accuracy were within $10 \%$. Zhao et al. [6] presented a numerical study of a counter flow Indirect Evaporative Cooler for sub-wet bulb temperature cooling. The authors suggested a range of design conditions to maximize the cooler performance including air velocity range, height of air passage, and length to height ratio of air flow ducts and found that the cooler can yield wet bulb effectiveness of up to 1.3. Riangvilaikul et al. [7] presented experimental results for a sensible evaporative cooling system at different inlet air conditions (temperature, humidity and velocity) covering dry, temperate and humid climates. The results show that wet bulb effectiveness ranged between 92 and 114\%. A continuous operation of the system during a typical day of summer season in a hot and humid climate showed that wet bulb effectiveness was almost constant at about $102 \%$. Hasan [8] also presented a theoretical model of four different configurations of indirect and sub wet bulb temperature coolers: two-stage counter flow cooler, two-stage parallel flow cooler, single-stage counter flow regenerative cooler and combined parallel-regenerative cooler. The author concluded that with higher number of staged coolers, the ultimate temperature to be reached is the dew point of ambient air.

\section{Wet Media Materials}

The wet media used in evaporative coolers is an essential component of an evaporative cooler. It is usually made of a porous material with large surface area and capacity to hold liquid water. According to Wanphen and Nagano [9], the selection of wet media materials is based on their effectiveness, availability, cost, safety, and environment factors. Zhao et al [10] investigated various types of porous materials such as metal and plastic foams, zeolite and carbon fibres to be used as wet media for heat and mass transfer in evaporative cooling systems. Musa [11] also investigated the use of more common aspen pads materials for indirect evaporative cooling system. Riffat and Zhu [12] employed ceramic materials for indirect evaporative cooling systems. Fig. 3 shows some common wet media materials that can be found in evaporative cooling systems.

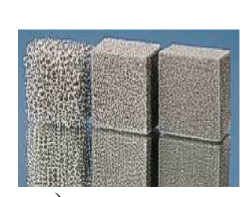
a) b)

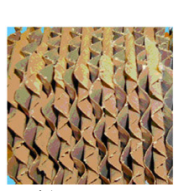
(Aspen) c) Celdek paper d) fired- clay.

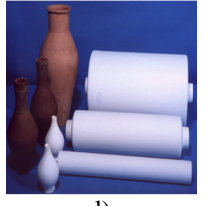

d) a) metal foams b) organic impregnated materials

\section{DESCRIPTION OF THE POROUS CERAMIC EVAPORATIVE COOLER}

In this project, porous ceramic materials in the form of hollow flat shells were used as wet media in a sub-wet bulb temperature evaporative cooler. Porous ceramic materials were selected for their stable structural, non-corrosion properties and easily moulded into desired shape. Fig. 4 shows the configuration of the sub-wet bulb temperature evaporative cooler using the porous ceramic material for water evaporation.

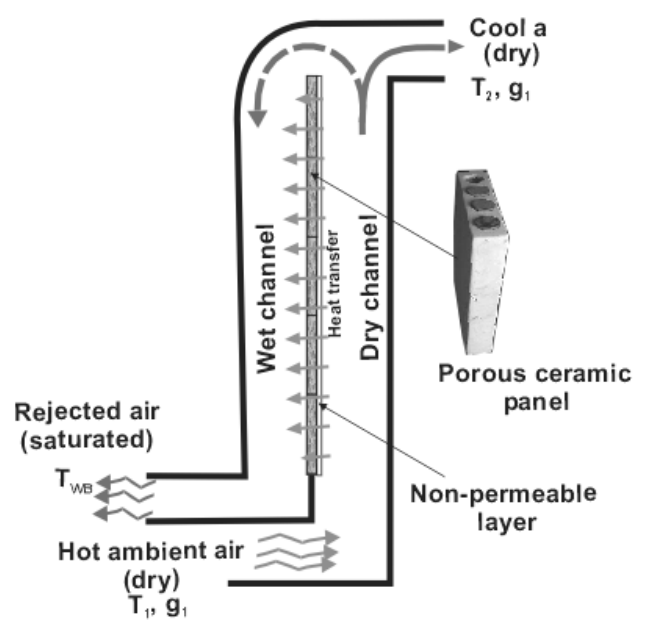

Fig. 4. A schematic of a building integrated sub-wet bulb temperature porous ceramic evaporative cooler

The porous ceramic panels were placed between the dry and wet air ducts to form small and narrow ducts with air flowing at low velocity. The dry channel side of the porous ceramic panel is sealed with a thin non-permeable membrane while the wet channel side allows water to sip through its micro-pores onto its surface forming a thin water film. This 
allows direct contact with the airflow and hence causing water evaporation. The air streams in the dry and wet channel flow in counter flow arrangement and the supply air exchanges sensible heat with the water in the porous ceramic panels that in turn are cooled through water evaporation on the wet channel side. This results in a drop in temperature of the air in the dry channel without changing its moisture content while the air in the wet channel is rejected at saturation state.

\section{MATHEMATiCAl Model}

The sub-wet bulb temperature evaporative cooler was modelled using common energy and mass conservation laws. In the model the dry and wet channel were divided into small elements (finite volumes) to which the energy and mass transfer equations were applied.

\section{A. Energy Conservation in the Dry Channel}

Air is cooled in the dry channel by transferring its sensible heat to the wet channel through the non-permeable layer and the porous ceramic panels. This can be expressed as follows:

$$
\frac{\dot{m}_{d} \partial h_{d}}{\partial A}=-U\left(T_{d}-T_{f w}\right)
$$

where $m_{d}, h_{d}, T_{d}$, A and $\mathrm{U}$ are the air flow mass rate, enthalpy, temperature, heat transfer coefficient and area of the dry channel. $T_{f w}$ is the temperature of the water film on the wet channel side.

\section{B. Energy Conservation in the Wet Channel}

The heat transfer mechanism in the wet channel is more complicated than in the dry channels, as sensible and latent heat is exchanged between the airflow and the water film on the surface of the porous ceramics. This is expressed as [13]:

$$
\frac{\dot{m}_{w} \partial h_{w}}{\partial A}=\kappa\left(T_{f w}-T_{w}\right)+\sigma\left(g_{f w}-g_{w}\right) h_{f g}
$$

where $m_{w}, h_{w}, T_{w}, g_{w}$, and $\kappa$ are the air mass flow rate, enthalpy, temperature, moisture content and convective heat transfer coefficient in the wet channel. $T_{f w}, g_{f w}$, and $\sigma$ are the water film temperature, saturated air moisture content, and mass transfer coefficient. It is assumed that air flow regime in both dry and wet channel are laminar and the mass transfer coefficient, $\sigma$ obeys the following Lewis number correlation [8], [13]:

$$
L e=\frac{\kappa}{\sigma c_{p}}
$$

where Lewis number, Le, value ranges from to 0.9 to 1.15 and to simplify the analysis it is often taken to be $1, c_{p}$ is specific heat of humid air.

\section{Mass Conservation in the Wet Channel}

Water evaporation from the ceramic panel surface appears as an increase of the air moisture content along the length of the wet channel. The mass balance for the water vapour in the wet channel can be written as:

$$
\frac{\dot{m}_{w}}{\partial A} \frac{\partial g_{w}}{\partial A}\left(g_{f w}-g_{w}\right)
$$

\section{Overall Energy Balance}

The overall energy and mass balance at the water film interface between the air flow in the dry channel, the water film on the ceramic surface and the air flow in the wet channel can be expressed as:

$$
\frac{\dot{m}_{f w} C_{p f w} \partial T_{f w}}{\partial A}=U\left(T_{d}-T_{f w}\right)-\sigma\left(g_{f w}-g_{w}\right) h_{f g}-\alpha\left(T_{f w}-T_{w}\right)
$$

where $C_{p f w}$ is specific heat of water.

The governing differential equations were discretised and applied to each finite volume element along the dry and wet channel length. In the computer model, it was assumed that the air properties, heat and mass transfer coefficients are constant in each finite control volume, the water film and the non-permeable membrane thermal resistances were assumed to be negligible.

The initial conditions used in this model include known air properties (temperature and moisture content) for the dry channel and air moisture content for the wet channel. The main design parameters of the system are given in Table I.

TABLE I: DESIGN AND MODELLING PARAMETERS

\begin{tabular}{|l|l|}
\hline Air channel Length & $0.64 \mathrm{~m}$ \\
Air channel Width & $0.93 \mathrm{~m}$ \\
Air channel Height & $0.005 \mathrm{~m}$ \\
Mass low rate in the dry channel & $0.03(\mathrm{~kg} / \mathrm{s})$ \\
Mass flow rate in the wet channel & $0.012(\mathrm{~kg} / \mathrm{s})$ \\
Air flow regime & $\mathrm{Laminar}$ \\
Fan power rating & $16-24 \mathrm{~V}, 14 \mathrm{~W}$ \\
Porous Ceramic & \\
materials composition & $\mathrm{Al}_{2} \mathrm{O}_{3}, \mathrm{SiO}_{2}, \mathrm{Si}_{3} \mathrm{~N}_{4}$ \\
Porosity & $17 \%$ \\
Density & $2300 \mathrm{~kg} / \mathrm{m}^{3}$ \\
Thermal conductivity & $1.5 \mathrm{~W} / \mathrm{mK}$ \\
\hline
\end{tabular}

Computation of the operating parameters of airflow along the air ducts length was performed iteratively until converging conditions were satisfied giving a temperature difference between two consecutive iterations of less than $0.01^{\circ} \mathrm{C}$.

\section{EXPERIMENTAL TEST Rig AND RESUlts}

A laboratory test rig was built to test the porous ceramic sub-wet bulb temperature evaporative cooler is shown in Fig. 5. The porous ceramic panels were filled with water through and overhead tank while a fan was used to draw air at controlled temperature and relative humidity from an environmental chamber and circulate it through the evaporative cooler dry and wet channels. The rig was fully instrumented to measure the air temperature, moisture content and flow rates along the dry and wet channels.

The thermal performance of the laboratory prototype was measured under controlled conditions of inlet air temperature and humidity. The results of which were also compared to that of the computer model. Fig. 6 shows the computer model 
and experimental results of the airflow temperatures in the dry and wet channel. For an initial inlet air flow (ambient conditions) dry bulb temperature of $35^{\circ} \mathrm{C}$ and relative humidity of $35 \%$ (i.e., wet bulb temperature of $23.1^{\circ} \mathrm{C}$ and dew point of $18^{\circ} \mathrm{C}$ ), the computer model predicts that the supply air could be cooled to $22.3^{\circ} \mathrm{C}$, achieving sub-web bulb temperature conditions. The airflow along the wet channel, on the other hand, increased from $22.3^{\circ} \mathrm{C}$ to $26.2^{\circ} \mathrm{C}$, as the balance between sensible heat loss to evaporate water on the surface of the ceramics and latent heat gain from the addition of water vapour to the air is positive. The experimental measurements however show the supply air is cooled to about $22.9^{\circ} \mathrm{C}$ and that of the rejected air from the wet channel is $23.2^{\circ} \mathrm{C}$. The discrepancy between the experimental and computer model results could be explained by the difficulties in obtaining a uniform air distribution in the wide section of the dry and wet channel.

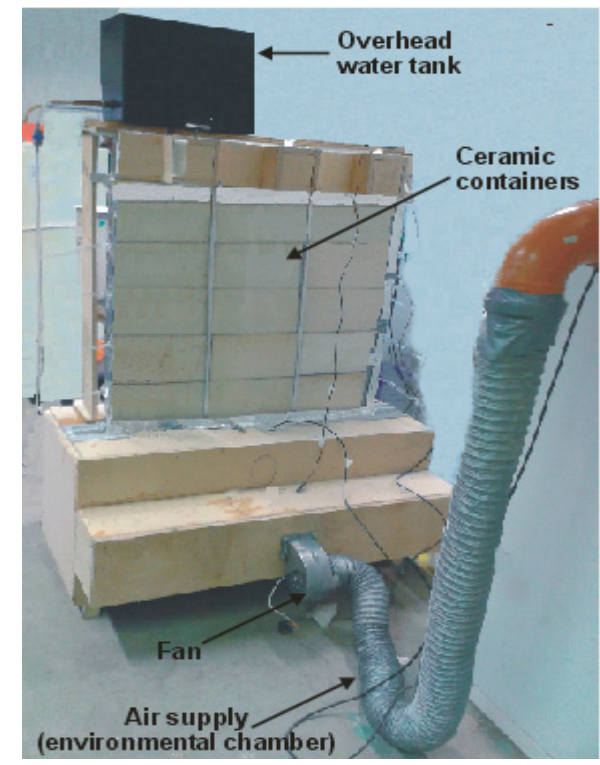

Fig. 5. A laboratory experiment rig of the ceramic evaporative cooler

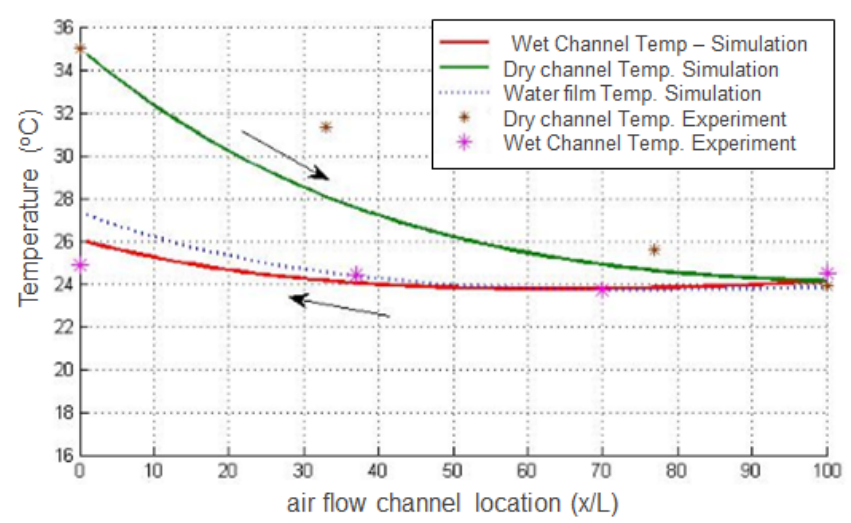

Fig. 6. Temperature profile along the dry and wet channel (air inlet from left to right) air mass flow rate $\mathrm{md}=0.03 \mathrm{~kg} / \mathrm{s}$

The experimental steady state temperature of the supply airflow, rejected air and water film were recorded as shown in Fig. 7. It can be seen that the supply airflow temperature (airflow in the dry channel) was reduced from the inlet conditions of $35^{\circ} \mathrm{C}$ to about $25^{\circ} \mathrm{C}$ (a drop of $10^{\circ} \mathrm{C}$ ) at a constant relative humidity of $35 \%$ and mass flow rate of $0.03 \mathrm{~kg} / \mathrm{s}$.

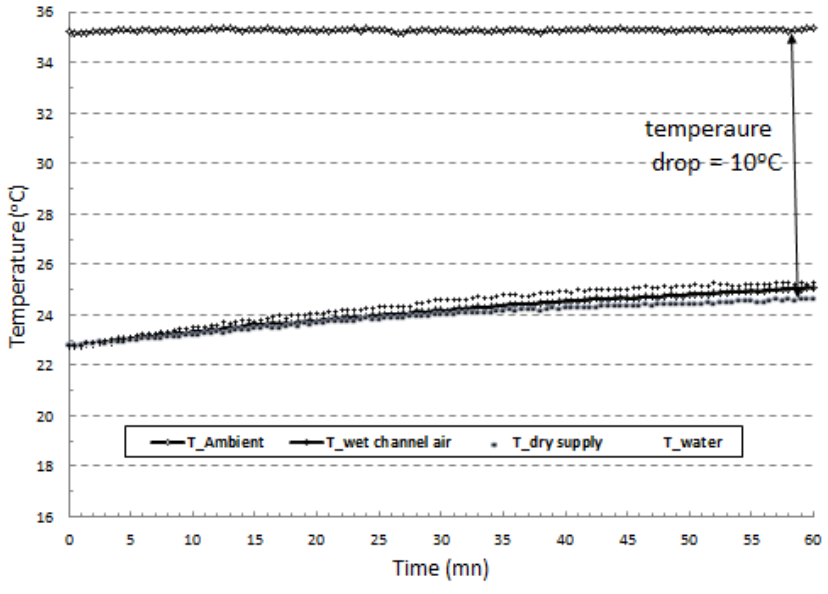

Fig. 7. Temperature evolution in the evaporative cooler $(\mathrm{md}=0.03 \mathrm{~kg} / \mathrm{s}$, $\mathrm{RH}=35 \%$ ).

Further evaluation of the performance of the evaporative cooler was carried out by calculating its cooling potential at various dry bulb temperature and relative humidity conditions, as shown in Fig. 8. It can be seen that the cooling capacity is strongly influenced by the dry bulb temperature and relative humidity of the ambient air. The cooling capacity decreased nearly proportionally to increasing relative humidity. This caused by the diminishing rate of water evaporation as the air in the wet channel nears the saturation conditions. The cooling capacity at $40^{\circ} \mathrm{C}$ and $35 \%$ relative humidity was measured to be about $240 \mathrm{~W} / \mathrm{m}^{2}$ of the wet porous ceramic surface area.

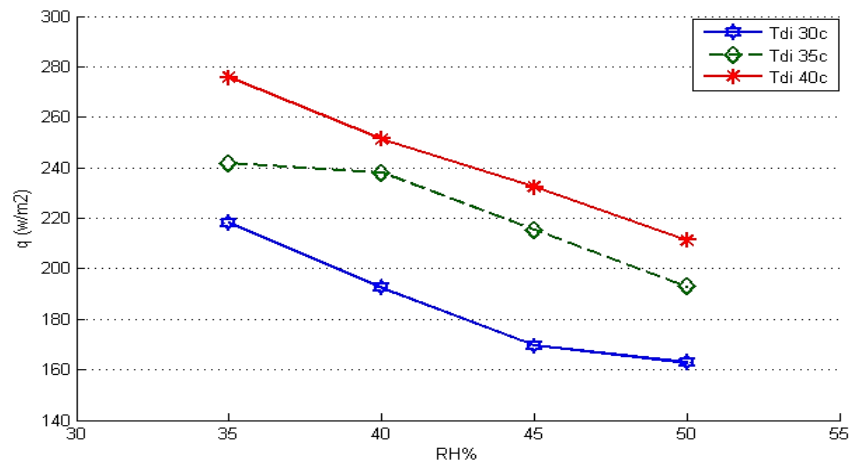

Fig. 8. Cooling capacity $\left(\mathrm{m}_{\mathrm{d}}=0.03 \mathrm{~kg} / \mathrm{s}\right)$.

Finally, the effectiveness of the evaporative cooler was determined using the wet bulb and dew point effectiveness. The wet bulb effectiveness is the ratio of the difference between inlet and outlet airflow dry bulb temperature to the difference between inlet airflow dry bulb temperature and its corresponding wet bulb temperature [14]. The mathematic expression of the wet bulb effectiveness is given by:

$$
\varepsilon_{w b}=\frac{T_{d b, \text { in }}-T_{d b, \text { out }}}{T_{d b, \text { in }}-T_{w b, \text { in }}}
$$

The dew point effectiveness, on the other hand, is the ratio of the difference between inlet airflow dry bulb temperature to the difference between inlet airflow dry bulb temperature and its dew point temperature [15]. The mathematic expression of the dew point effectiveness is expressed as follows: 


$$
\mathcal{E}_{d p}=\frac{T_{d b, \text { in }}-T_{d b, o u t}}{T_{d b, \text { in }}-T_{d p}}
$$

For a typical inlet airflow condition of $35^{\circ} \mathrm{C}$ and $35 \%$ relative humidity, the web bulb effectiveness of experimental test was 1.02 and dew point effectiveness was 0.712 . This shows that the evaporative cooler achieved wet bulb effectiveness greater than unity, a thermal performance that could compare favourably with mechanical vapour compression systems used in hot climates with the additional benefit of improving comfort level in buildings.

\section{CONCLUSION}

A computer model and experimental results of a sub-wet bulb temperature evaporative cooler using porous ceramic materials were presented. It was shown that the evaporative cooler can achieve high thermal performance in terms of low air supply temperatures and effectiveness. The structural stability and manufacturing controllability of ceramic materials lend them well to integration into buildings and performing the function of air conditioning in regions with hot and dry climatic conditions.

\section{REFERENCES}

[1] A. Dodoo, L. Gustavsson, and R. Sathre, "Building energy-efficiency standards in a life cycle primary energy perspective," Energy and Buildings., vol. 43, no. 7, pp. 1589-1597, 2011.

[2] D. R.Vissers, "Study on Building integrated evaporative cooling of glass-covered spaces, in Building Physics and Systems," Eindhoven University of Technology, 2011.

[3] W. P. Jones, Air Conditioning Engineering, $5^{\text {th }}$ Edition, Butterworth Heinemann, 2001.

[4] S. T. Hsu, Z. Lavan, and W. M. Worek, "Optimization of wet-surface heat exchangers," Energy, vol. 14, pp. 757-770, 1989.

[5] G. Boxem, S. Boink, and W. Zeiler, "Performance model for small scale indirect evaporative cooler," in Proceedings of Clima WellBeing Indoors, REHVA World Congress, Helsinki, Finland, 2007, No.1676.

[6] X. Zhao, J. M. Li, and S. B. Riffat, "Numerical study of a novel counter-flow heat and mass exchanger for dew point evaporative cooling," Applied Thermal Engineering, vol. 28, no. 14-15, pp. 1942-1951, 2008.

[7] B. Riangvilaikul and S. Kumar, "An experimental study of a novel dew point evaporative cooling system," Energy and Buildings, vol. 42, pp $637-644,2010$

[8] A. Hasan, "Indirect evaporative cooling of air to a sub-wet bulb temperature," Applied Thermal Engineering., vol. 30, no. 16, pp. 2460-2468, 2010.

[9] S. Wanphen and K. Nagano, "Experimental study of the performance of porous materials to moderate the roof surface temperature by its evaporative cooling effect," Building and Environment, vol. 44, no. 2, pp. 338-351, 2009.
[10] X. Zhao, Z. Duan, C. Zhan, and S. B. Riffat, "Dynamic performance of a novel dew point air conditioning for the UK buildings," International Journal of Low Carbon Technologies, vol. 4, pp. 27-35, 2009.

[11] M. Musa, "Novel Evaporative Cooling Systems for Building application, in Architectur and Built EnvironmentMay," $\mathrm{PhD}$ thesis, The University of Nottingham: Nottingham, pp. 61-70, 234, 2008.

[12] S. B. Riffat and J. Zhu, "Mathematical model of indirect evaporative cooler using porous ceramic and heat pipe," Applied Thermal Engineering, vol. 24, no. 4, pp. 457-470, 2004.

[13] B. Halasz, "A general mathematical model of evaporative cooling devices," Elsevier, Paris, pp. 245-255, 1998.

[14] B. Riangvilaikul and S. Kumar, "Numerical study of a novel dew point evaporative cooling system," Energy and Buildings, vol. 42, no. 11, pp. 2241-2250, 2010.

[15] B. Frank, "On-site experimental testing of a novel dew point evaporative cooler," Energy and Buildings, vol. 43, no. 12, pp. 3475-3483, 2011.

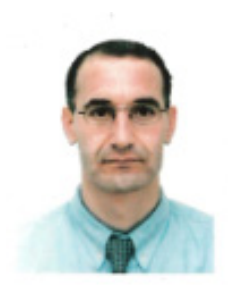

R. Boukhanouf is a lecturer in sustainable energy technologies at the Department of Built Environment, University of Nottingham. His experience in research and teaching in the area of energy efficient and low carbon technologies extends for over 15 years. He obtained his $\mathrm{PhD}$ in 1996 from the University of Manchester, UK.

Dr. Boukhanouf worked on numerous research projects funded by industry and government agencies in the area of small scale combined heat and power, active and passive heating and cooling systems for buildings, and advanced heat transfer enabling devices. He published a number of journal and conference papers and is named as the inventor in six international patents.

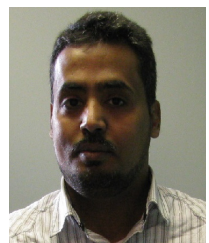

A. Alharbi is a $\mathrm{PhD}$ degree candidate in the department of the Built Environment, University of Nottingham. His main research topic is evaporative cooling technology in hot and dry climates. Mr. Alharbi has a MSc and BEng degree in mechanical engineering. He has a long industrial experience in air conditioning systems.

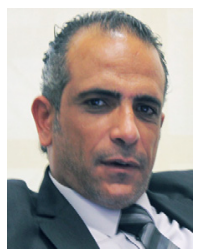

H. G. Ibrahim is an associate professor at Qatar University. Dr. Ibrahim has a long and established research experience including managing green construction, carbon abatement in construction industry using knowledge based programming, and preservation of traditional architectural and urban heritage of Qatar. The latter being particular an ass-on advantage for reconciling the integration of new low carbon technologies with the traditional architectural concepts.

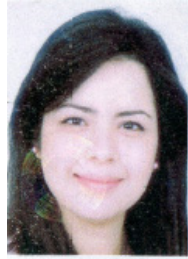

Meryem Kanzari is currently a research assistant at Qatar University and working on a novel design of evaporative cooling system for application in hot and dry climates. Previously, she worked on various engineering projects including time frequency analysis of vibration and acoustic systems, fault detection and industrial maintenance and instrumentation. Ms Kanzari obtained Engineer degree from Institut National des Sciences Appliquées et de Technologie (INSAT), TUNISIA, in 2008 and a MSc degree from Institut National des Sciences Appliquées de Lyon (INSA Lyon), FRANCE in 2009. 